\title{
Damping of nanocrystalline materials: a review
}

\author{
R.R. Mulyukov ${ }^{1, \dagger}$, A.I. Pshenichnuk 1 , J.A. Baimova ${ }^{1,2}$ \\ †radik@imsp.ru
}

\author{
${ }^{1}$ Institute for Metals Superplasticity Problems, RAS, Khalturina 39, 450001, Ufa, Russia \\ ${ }^{2}$ M.N. Miheev Institute of Metal Physics of Ural Branch of RAS (IMP UB RAS), Kovalyevskoy 18, 620990, Ekaterinburg
}

\begin{abstract}
High defect concentration and non-equilibrium state of nanocrystalline materials can lead to considerable increase of damping capacity, thus the investigation of dumping of the nanocrystalline metals produced by severe plastic deformation is of high importance nowadays. In this review, the latest achievements on the studying of the damping and structure of nanocrystalline materials are discussed for different metals and alloys. The results for amplitude and temperature dependences on internal friction for nanocrystalline metals and alloys prepared by different methods are presented. The results received for amplitude dependence of internal friction are analyzed in the connection with the mechanisms of dissipation of grain and grain boundary dislocations. The comparison of Bordoni, Snoek-Koster and grain boundary peaks, which were found on the temperature dependence of the internal friction is presented for metals in two states: nanocrystalline and coarse grained. After a brief overview of the production of nanocrystaline materials, the focus is set on the damping and structure as well as some mechanical properties of these materials. Both experimental and theoretical investigations of damping capacity in connection with strength properties together with some typical examples are presented. Open issues in the development of nanocrystalline materials with high internal friction are discussed in the conclusion section.
\end{abstract}

Keywords: damping, nanocrystalline materials, internal friction.

The intrinsic mechanical damping (or internal friction) is defined as the capacity of the material to convert its mechanical energy of vibration into heat that is dissipated in the material. High damping materials [1,2] allow undesirable mechanical vibration and wave propagation to be passively suppressed which can be effectively used, for example, in the control of noise, the enhancement of vehicle and instrument stability, ets. [3,4]. Application of damping properties of materials are to be expected in situation where the occurrence of the mechanical vibrations has to be reduced below some critical value. The necessity of limiting vibration amplitudes can be an intrinsic requirement for the correct operation of the whole system or contribute to its useful life time. Meanwhile, the increase of damping by traditional methods results in reducing the strength properties [4]. At the same time, the formation of ultrafinegrained structure in pure copper leads to the increase of both the amplitude independent damping (internal friction) and the yield strength [5]. The combination of high damping and strength properties is very important for the development of new metallic materials subjected to cyclic deformation. Contrary to their wide application, there is some confusion in understanding of the physical mechanisms which lead to high intrinsic damping in metallic materials. Moreover, the consideration of damping capacity in connection with other mechanical properties is of high importance.

Crystalline defects, for example, grain boundaries (GB), can lead to the increase of internal friction, thus, it is very important to study nanocristallyne (NC) with grain size about $100 \mathrm{~nm}$ and ultrafine grain materials where a lot of GBs can be found. Such materials, exhibiting many interesting and unique properties, can be effectively produced by severe plastic deformation (SPD) [6-11]. The peculiarities of NC materials define the appearance of wide relaxation peaks observed in experiments [12-16]. It was already shown that some NC metals and alloys produced by SPD can exhibit relatively high damping due to a contribution of grain boundary dislocations in combination with a significant increase in yield strength as compared with the non-deformed state.

This review is concerned with the production of NC metallic materials with high damping capacity. Despite, the subject of high damping NC materials was discussed for last 20 years, there is still plenty of room for studying of the physical mechanisms which lead to high intrinsic damping and, which is more important, for investigation of increased damping without any loss in the strength. The review is designed to present fundamental studies on NC materials with high damping properties, summarize recent results and arise new issues in the field.

High damping of the materials can have different physical nature. A high damping capacity is considered as one of the important functional properties of shape memory alloys [17-20]. Mechanical damping is also can be found for magnetic alloys [21], for pure magnesium [22-27] and magnesium alloys $[22,26,28]$, to name a few. Higher damping capacity was found also for ZK60 and AZ91 alloy after SPD $[5,29,30]$.

The value of damping capacity can be changed by different methods. It was shown that for materials without pre-strain, the damping capacity consisted of the strainindependent and the strain-dependent parts, which emerged above a critical strain. The critical strain observed for the 
damping capacity corresponded to the proportional limit observed for the tensile or compressive curves. For materials pre-strained to $\sim 1 \%$ and $\sim 8 \%$ in the extrusion direction, the damping capacity began to increase at low strains below the proportional limit and was higher than that without pre-strain. The higher damping capacity is thought to occur because of the alternate shrinkage and growth of pre-existing twins. The other possible ways to affect the damping properties of metallic materials is training-treatment [31], heat treatment [32] and dynamic lading [33]. Interestingly, internal friction in NC palladium can be affected by hydrogen isotops [34]. The data demonstrate a strong hydrogen-induced internalfriction peak at around $160 \mathrm{~K}$. The comparison the results for H-doped ordinary coarse-grained or single-crystal Pd suggests that the peak is caused by a Snoek-Koster relaxation of $\mathrm{H}$ or $\mathrm{D}$ atoms in the grains of the NC Pd.

The other powerful method of modification of damping properties of the material which is discussing in the present review is the SPD of metals and alloys. Among the internal friction mechanisms, the energy dissipation by the movement not only of grain but also grain-boundary dislocation movement is very important, which is quite actual for materials after SPD. It was already shown that the intrinsic damping capacity of quasicrystalline $\mathrm{Al}-\mathrm{Cu}-\mathrm{Fe}$ is found to increase progressively with the temperature in the whole strain amplitude range. It was found that decrease of the grain size to the nanoscale values leads to a significant increase of damping capacity at temperatures above $520 \mathrm{~K}$ [35] (see fig. 1).

The strain amplitude and temperature dependences of the internal friction of the nanocrystalline copper formed by equal-channel angular pressure (ECAP) was studied in $[5,15,36]$. The example of the microstructure after SPD is shown in Fig. 2 for copper. The transmission electron microscopy (TEM) observations show that SPD leads to the formation of a granular type of structure with equiaxial grains of mean grain size approximately $200 \mathrm{~nm}$. The dependence of internal friction on the amplitude of deformation was measured at room temperature with the use of a torsion pendulum. The measurements were made at a frequency of approximately $35 \mathrm{~Hz}$. The temperature dependence of internal friction was determined in an inverted torsion pendulum with a deformation amplitude of $10^{-5}$.

The background and strain amplitude dependence of the internal friction in copper are presented in Fig. 3. It can be seen, that in intensively deformed samples and those subjected to subsequent annealing at $150{ }^{\circ} \mathrm{C}$ there is a high level internal friction background and a relatively low amplitude dependence $\delta$. The background level $\delta_{f}$ in thin samples is two to three times higher than in grey cast iron $\left(50 \cdot 10^{-4}\right)$, which is usually taken as the basis for the comparison of high damping metals and alloys $[2,4]$. According to the character of the curves of the strain amplitude dependence of the internal friction in NC copper, the strain amplitude at which microplastic deformation occurs decreases with increasing grain size. The results of the tensile tests confirm this. On increasing the annealing temperature, the strain amplitude dependence of the internal friction increases. The background decreases sharply at $175^{\circ} \mathrm{C}$ until it reaches values typical for low damping materials such as normal coarse- grained copper. From the measurements of the background and strain amplitude dependence of the internal friction it follows that amplitude-independent internal friction damping at low strains in $\mathrm{Cu}$ with the NC structure and nonequilibrium GBs is three to five times higher than in normal coarse-grained copper.

Above ambient temperature the internal friction increases to high values of about $\delta=6 \cdot 10^{-2}$ which are rapidly reduced by annealing between 400 and $500 \mathrm{~K}$. After annealing at $500 \mathrm{~K}$, a small internal friction maximum at $485 \mathrm{~K}$ appears to be superimposed to the continuously increasing internal friction background. At about $53 \mathrm{~K}$, a Bordoni peak, which is wellknown as the internal friction peak due to dislocation motion observed in the deformed fcc metals, with a maximum value of $\delta=1.5 \cdot 10^{-3}$ is found which disappears after annealing at $500 \mathrm{~K}$. With a value $\delta=0.5 \cdot 10^{-3}$ below $240 \mathrm{~K}$ the internal friction in $\mathrm{NC} \mathrm{Cu}$ is lower than in well annealed polycrystalline $\mathrm{Cu}$ (see Fig. 4) [36]. At higher temperatures a strong damping up

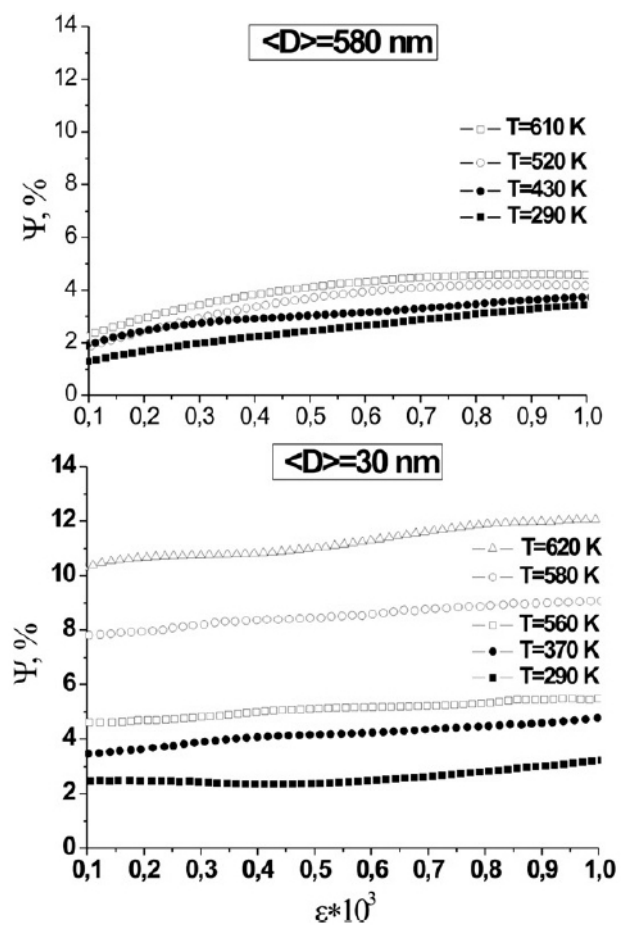

Fig. 1. Dependence of damping capacity of $\mathrm{Al}-\mathrm{Cu}-\mathrm{Fe}$ material, having different average grain size $\langle D\rangle$, on the strain amplitude. Reprinted with the permission from [35].

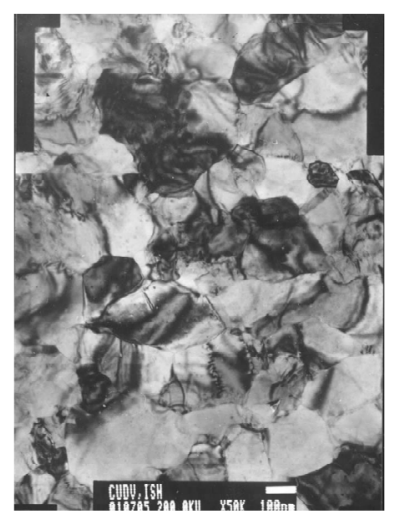

Fig. 2. Microstructure of SPD copper. Reprinted with the permission from [36]. 
to $\delta=6 \cdot 10^{-2}$ occurs. At the same time, the tensile tests have shown that the yield stress $\sigma_{02}$ of the sample immediately after severe deformation amounts to $390 \mathrm{MPa}$, which is five times higher than in coarse-grained copper. Thus, the for $\mathrm{NC} \mathrm{Cu}$ both damping and strength characteristics are much higher than for coarse-grain $\mathrm{Cu}$.

The other good example of high damping properties is Aluminum: Al sheets after accumulative rolling bonding exhibiting high damping capacity as well as high strength was shown in [37]; effect of the microstructure evolution on damping capacity of pure $\mathrm{Al}$ processed by ECAP was studied in [38]; low-temperature internal friction spectrum of NC Al was studied in [39], where internal friction peak accompanied by a modulus defect was observed at around
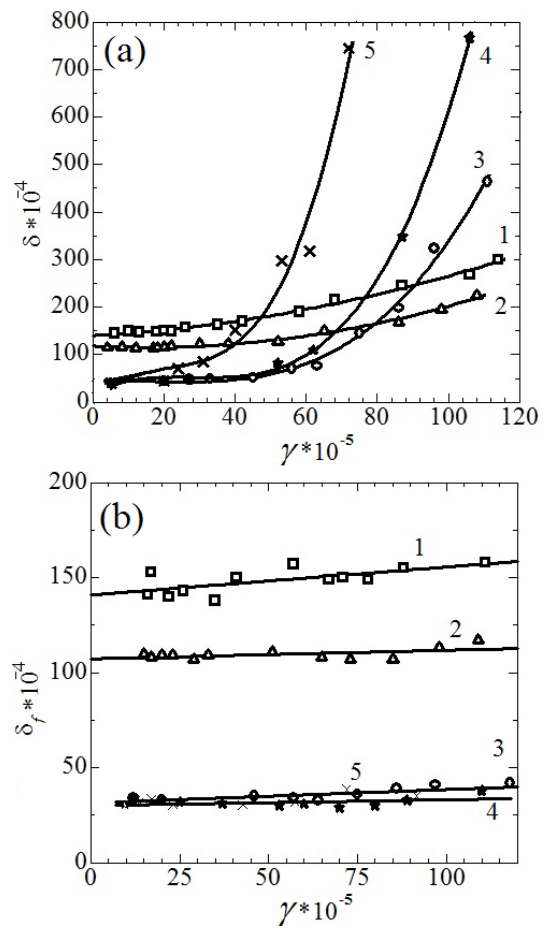

Fig. 3. Strain amplitude dependence of (a) internal friction and (b) internal friction background in copper after severe deformation (curve 1) and subsequent annealing for $1 \mathrm{~h}$ at room temperatures of 150 (curve 2), 175 (curve 3), 250 (curve 4) and 350 oC (curve 5). Points correspond to the experimental data while curves correspond to the phenomenological calculations. Reprinted with the permission from [36].

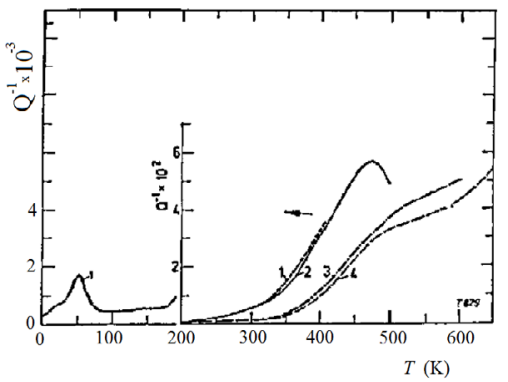

Fig. 4. Temperature dependence of internal friction of NC copper configuration. If we assume that dissipation of mechanical measured at several subsequent steps of heating (from 1 to 4). Low energy in NC material is determined by the total area of temperature part with Bordoni peak at $54 \mathrm{~K}$ (step of heating after starting boundaries swept by all dislocations, then at high density measurements at 240 $\mathrm{K}$ ) is given for an internal friction scale increased of GBD we should have high values of $\mathrm{d}$, but weak by 10 times. Reprinted with the permission from [36].
130 K. Pure Al prepared by ECAP [38] shows that ultra-fine grained state of metal demonstrates damping capacity that is enhanced in comparison with coarse-grained one, especially when the temperature is higher than $60^{\circ} \mathrm{C}$. The dependences similar to one for $\mathrm{Cu}$ (Fig. 3) are observed for pure $\mathrm{NC} \mathrm{Al}$. As it can be seen from Fig. 3, during heating from 20 to $150^{\circ} \mathrm{C}$, the damping capacity Q-1 increases monotonically. As to the dependence of the frequency, the lower the frequency is, the better the damping capacity. It is observed that the damping capacity increases rapidly as the strain amplitude increases; however, when the strain amplitude reaches a certain value, the increasing of the damping capacity becomes slow. The damping capacity shows a typical dependence on the strain amplitude, i.e. a significant nonlinear internal friction character. At the lower strain amplitude, the damping capacity of both cases is quite the same, while with the increasing of the strain amplitude the sample as prepared by ECAP without annealing shows higher damping capacity than that with annealing. Figure $5 \mathrm{~b}$ shows that the damping capacity is attributed to the dislocation movement. As pointed out in [37], the ultra-fine grained structure will make the dislocation's movement being limited in a certain area because the ends of the dislocation are tightly bounded by the grain boundary, which results in that the damping capacity will not change when the strain amplitude is accessing a certain value.

For $\mathrm{NC} \mathrm{Cu}$ and $\mathrm{Al}$, the plots of loss factor versus strain amplitude for different grain sizes calculated by finite element method are shown in Fig. 6 (the fixed grain boundary size $2.5 \mathrm{~nm}$ is used) [40]. It is noteworthy that for NC material, the strain amplitude-independent part of plots (i.e. $\mathrm{Cu}$ at $\varepsilon_{0} \leq 0.004$ and $\mathrm{Al}$ at $\varepsilon_{0} \leq 0.002$ as it is shown in Fig. 6) is higher than ordinary material because of stress concentration. As the grain size decreases, greater strain values are needed to
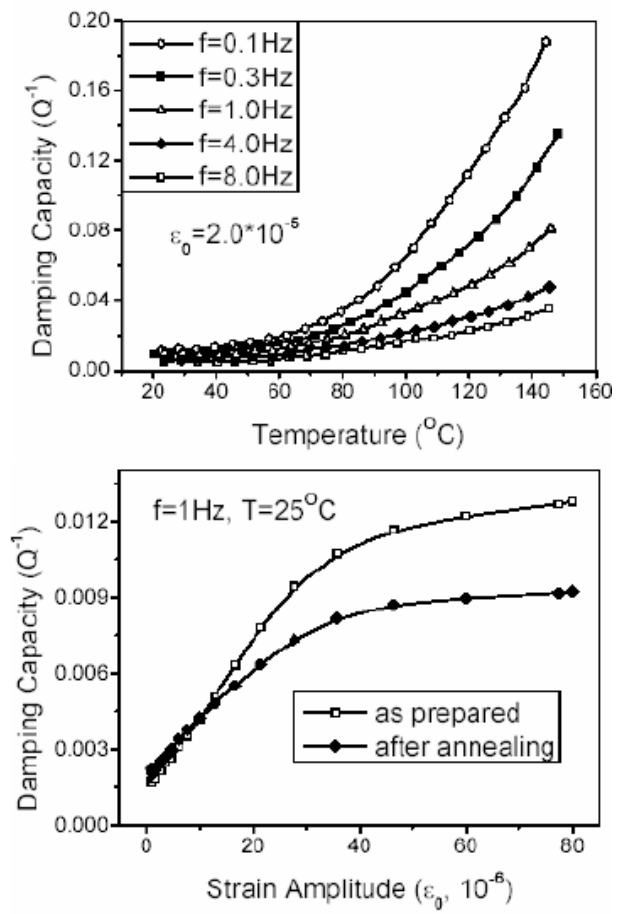

Fig. 5. (a) Temperature dependence of the damping capacity for the commercially pure Al prepared by ECAP. (b) The damping capacity $\left(\mathrm{Q}^{-1}\right)$ of ECAP processed pure $\mathrm{Al}$ as a function of the strain amplitude $\left(\varepsilon_{0}\right)$. Reprinted with the permission from [38]. 
obtain the same damping capacity. As the grain size decreases, the material hardens and yielding took place at higher strain values; thus, to achieve a specific damping capacity, a higher strain value is required. It has been shown that as the grain size decreases, strain value domain for damping behavior changes [40]. Three deformation steps can be recognized in deformation of NC materials: in each step, a special damping behavior can be observed.

The amplitude dependence of the internal friction of the $18 \mathrm{Cr}-10 \mathrm{Ni}$ stainless steel [41] is qualitatively analogous to the same dependences for copper. Especially high values of the background are observed after annealing at $650^{\circ} \mathrm{C}$ (Fig. 7, a). Further rise in the temperature results in increasing the amplitude dependence of the internal friction and decreasing the background to a value typical for coarse-grained austenitic steel. The exception is the annealing at $800^{\circ} \mathrm{C}$, which results in some increase of the background. The yield strength of the NC steel after deformation at $-196^{\circ} \mathrm{C}$ is four times higher as compared to the coarse-grained samples (1380 MPa for NC steel compared to $265 \mathrm{MPa}$ for coarse-grained steel, see Fig. $7, \mathrm{~b}$ ). When the temperature of annealing is increased to $650^{\circ} \mathrm{C}$ an additional increase in $\sigma_{02}$ by $15 \%$ is observed. Further temperature increase results in decreasing the yield strength value, which approaches that of coarse-grained steel and becomes three times less than the $\sigma_{02}$ value of the deformed sample after its annealing at $650^{\circ} \mathrm{C}$. The simultaneous consideration of the data for the internal friction and yield strength, as well as structural changes allows to give a conclusion about the improvement of damping and strength properties: the notable result is the sharp rise in the internal friction background and the maximum value of $\sigma_{02}$ observed in the deformed samples of steel after annealing at $650^{\circ} \mathrm{C}$.

Besides the numerical calculation and experiments, some theoretical models which were developed for the description

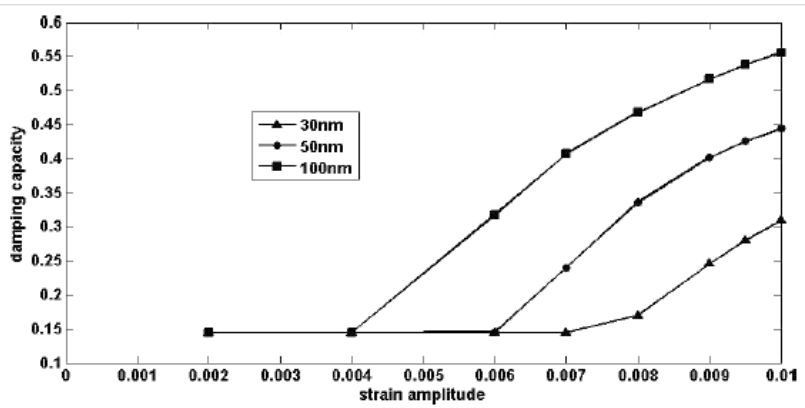

(a)

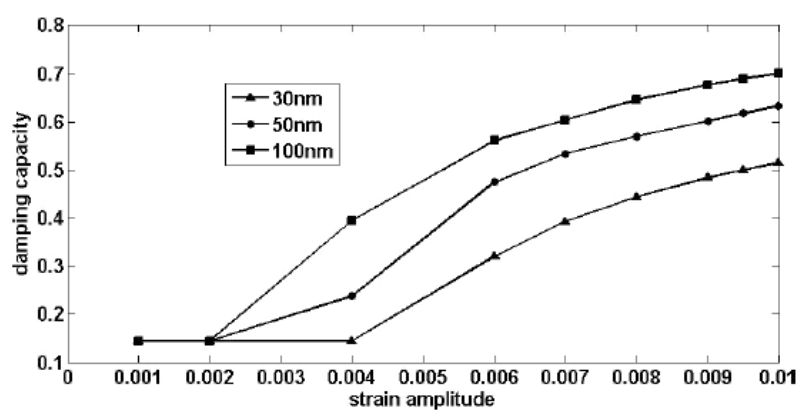

(b)

Fig. 6. Effect of grain size on damping: (a) $\mathrm{NC} \mathrm{Cu}$ and (b) $\mathrm{NC} \mathrm{Al}$. Calculation done by finite element method. Reprinted with the permission from [40]. of damping behavior of NC materials should be mentioned. A model NC material under external stress was considered in [42], based on the previous experimental results on NC materials $[12,13,14,15,43,44]$, to study the internal friction by diffusion model. The spectrum of the grain-boundary internal friction obtained with the present model consists of two maxima and a high-temperature background. The maxima are of a relaxation type and are associated either with impurity redistribution in nonuniformly strained boundaries or with grain sliding between triple intergranular joints.

The phenomenological analysis of the dissipation of mechanical energy in NC materials which is based on the experimental data was done in [36], where energy dissipation was connected with processes occurring at GBs. The sluggishness of dislocations was neglected and assumed that grain boundary dislocation (GBD) pileups keep track of the external load, i.e. distribution of dislocations at each moment of time is an equilibrium configuration. After this assumption, at high density of GBD the value of $\delta$ also should be high and amplitude dependence - weak, since the external field cannot compete with the internal stresses field of pile-ups. Annealing resulted in the decrease of both the power of GBD pile-ups and the local density, since with increasing grain size the length of boundaries increases at which GBD pile-up is distributed. This leads to the decrease in $\delta$ at small $\gamma$, but the much stronger dependence of $\delta$ on the amplitude of deformation, since the intrinsic field of the pile-up damps the external load to a lesser degree. These notions qualitatively fit the obtained experimental results.

Experimental data is well described by the two-parameter functional dependence:

$$
\delta=\alpha \cdot I_{0} \cdot(\beta \cdot \varepsilon)
$$

where $I_{0}$ is the modified function of Bessel, values of phenomenological parameters $\alpha, \beta$ (defined from experiment). It is clear that under the context of the concept proposed the following proportionality should be fulfilled $\alpha \sim n, \beta \sim n^{-1}$ ( $n$ is the number of movable dislocations). This fits well the obtained estimations of the values of these parameters.

\section{Summary}

In conclusion the development of high damping materials which are interesting for mechanical engineering is of high importance. From this point of view, metals and alloys which combine high damping capacity with good strength
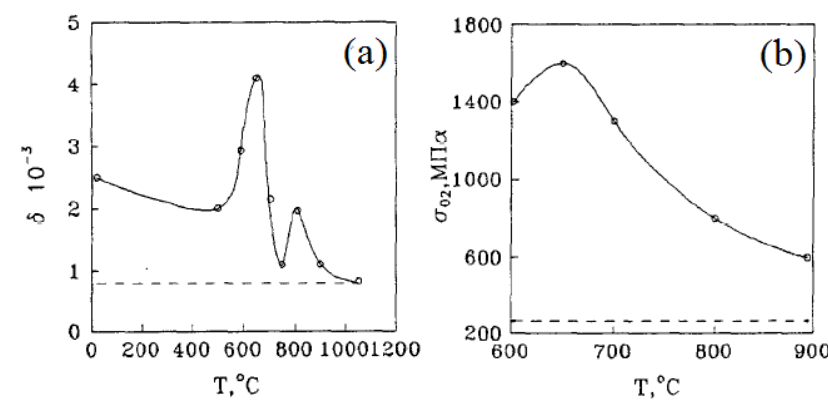

Fig. 7. (a) Dependence of the internal friction background and (b) dependence of the yield strength $\sigma_{02}$ on the temperature of annealing for the $18 \mathrm{Cr}-10 \mathrm{Ni}$ stainless steel. Dashed lines correspond to the values for the coarse-grained state. Reprinted with the permission from [41]. 
properties can provide attractive technical and economic solutions to problems involving fatigue, noise and vibration. An unceasing interest in the area of vibration analysis as well as design and construction of vibration-resistant structures is observed.

Since the increase in the damping of material by various methods quite often results in a decrease in their strength properties as a rule [4], it is very important to produce materials with both high damping and strength. It is shown that SPD can be successfully used for production of such materials $[43,44]$. For example, at low strain amplitudes the NC copper (after SPD) displays a considerable damping ability (three to five times higher than in the normal coarse-grained state) and higher strength properties (yield stress increases fivefold and microhardness increases more than threefold). The similar phenomenon was found for $18 \mathrm{Cr}-10 \mathrm{Ni}$ stainless steel, where the sharp increase both in the internal friction and yield strength is found. This behavior is attributed to the formation of a structure containing $\mathrm{NC}$ austenite grains with non-equilibrium GBs. A contribution of dispersed carbide particles can also be taken into account for this behavior. However, the value of this contribution is an open question and needs further investigations. Theoretical model, developed in [36], allows to phenomenologically describe experimental data and explain physical mechanisms of increase in internal friction. Such theoretical models can be very helpful for the understanding of physical processes which can lead to better damping properties and predict the damping behavior of some metallic materials.

The value of background of internal friction at different temperatures corresponds to the temperature dependence of internal friction measured at small values of deformation. The characteristics of the relaxation, Bordoni, Snoek-Koster and grain boundary peaks on the temperature dependences of internal friction are determined by the characteristics of the structure and physical properties of NC materials.

Competitively to the numerous applications of high damping materials, there is still luck of information about the ways of improving damping properties and in the development of good theoretical models. A better understanding of the effect of the various internal and external parameters on the observed damping levels and on their stability is expected with the aim to increase the possibilities for industrial applications of these materials.

\section{References}

1. I.S. Golovin. Key Engineering Materials. 319, 225 (2006).

2. I. G. Ritchie, Z.-L. Pan and F. E. Goodwin, Metall. Trans. A. 22, 617 (1991).

3. D.W. James. Mater. Sci. Eng. 4, 1 (1969).

4. Yu.K. Favstov, Yu.N. Shulga and A.G. Rakhshtadt, Metallic Material Science of High Damping Alloys, p. 272, Metallurgia, Moscow (1980) (in Russian).

5. R. R. Mulyukov, N. A. Akhmadeev and R. Z. Valiev, S. B. Mikhailov. Mat. Sci. Eng. A. 171, 143 (1993).

6. R.R. Mulyukov. Nanotechnologies in Russia. 2(7-8), 38 (2007).

7. S. Sabbaghianrad, T.G. Langdon. Letters on Materials.
5(3), 335 (2015).

8. M. Kawasaki, R.B. Figueiredo, T.G. Langdon. Letters on Materials. 5(3) 233 (2015).

9. O. S. Sitdikov. Letters on Materials. 5(1), 74 (2015).

10. I.I. Musabirov, I.M. Safarov, R.R. Mulyukov, I.Z. Sharipov, V.V. Koledov. Letters on Materials. 4(4), 265 (2014).

11. T.G. Langdon, Acta Mater. 61, 7035 (2013).

12. W.N. Weins, J.D. Makinson, R.J. De Angelis et al. Nanostr. Mater. 9, 509 (1997).

13. E. Bonetti, L. Pasquini, E. Sampaolesi. Nanostr. Mater. 10(3), 437 (1998).

14. B. Cai, Q.P. Kong, P. Cui at al. Scr. Mater. 44(7), 1043 (2001).

15. R. Mulyukov, M. Weller, R. Valiev et al. Nanostr. Mater. 6, 577 (1995).

16. E. Bonetti, E.G. Campari, L. Del Bianco et al. Nanostr. Mater. 6, 639 (1995).

17. Y. Watanabe, Y. Suga, H. Sato, H. Tsukamoto, Y. Nishino. Materials Transactions. 54(8), 1288 (2013).

18. J. San Juana, M.L. No. Journal of Alloys and Compounds. 355,65 (2003).

19. Y. Chen, H.C. Jiang, S.W. Liu, L.J. Rong, X.Q. Zhao. Journal of Alloys and Compounds 482, 151 (2009).

20. A. Amini, H. Beladi, N. Hameed, Frank Will. Journal of Alloys and Compounds 545, 222 (2012).

21. H.R. Salva, L.M. Fabietti, A.A. Ghilarducci, S.E. Urreta. Journal of Alloys and Compounds. 495, 420 (2010).

22. G.E. Mann, T. Sumitomo, C.H. Cáceres, J.R. Griffiths, Mater. Sci. Eng. A 456, 138 (2007).

23. Y. Li, M. Enoki, Mater, Trans. 48, 2343 (2007) .

24. Y. Li, M. Enoki, Mater. Trans. 49, 1800 (2008).

25. Y. Li, M. Enoki, J. Mater. Res. 26, 3098 (2011).

26. C.H. Cáceres, T. Sumitomo, M. Veidt, Acta Mater. 51, 6211 (2003).

27. H. Watanabe, Y. Sasakura, N. Ikeo, T. Mukai. Journal of Alloys and Compounds. 626, 60 (2015).

28. S.H. Chang, S.K. Wu, W.L. Tsai, J.Y. Wang. Journal of Alloys and Compounds. 487, 142 (2009).

29. V.N. Chuvildeev, T.G. Nieh, M.Yu. Gryaznov, A. N. Sysoev V. I. Kopylov: Scripta Materialia 50, 861 (2004).

30. V.N. Chuvildeev, T.G. Nieh, M.Yu. Gryaznov, V.I. Kopylov, A.N. Sysoev: Journal of Alloys and Compounds 378, 253 (2004).

31. Y. Watanabe, H. Sato, Y. Nishino, I.-S. Kim. Mat. Sci. Eng. A. 521-522, 376 (2009).

32. A. Flejszar, A. Mielczarek, G. Vidrich,W. Riehemann. Mat. Sci. Eng. A. 521-522, 299 (2009).

33. A. Amini, H. Beladi, N. Hameed, F. Will. Journal of Alloys and Compounds. 545, 222 (2012).

34. B. Kappesser, U. Stuhr, H. Wipf, J. Weibmuller, C. Klos, H. Gleiter. Journal of Alloys and Compounds. 231, 337 (1995).

35. A.I. Ustinov, S.S. Polishchuk, V.S. Skorodzievskii, V.V. Bliznuk. Surface \& Coatings Technology. 202, 5812 (2008).

36. R.R. Mulyukov, A.I. Pshenichnyuk. Journal of Alloys and Compounds. 355, 26 (2003).

37. Y. Koizumi, M. Ueyama, N. Tsuji, Y. Minamino , K. Ota: Journal of Alloys and Compounds 355, 47 (2003).

38. J. Wang, Z. Zhang, G. Yang. Key Engineering Materials. 319, 109 (2006). 
39. F.Tang, H.Tanimoto and S.Okuda. NanoStructured Materials. 6, 563 (1995).

40. M. Yadollahpour, S. Ziaei-Rad, F. Karimzadeh. International Journal of Modeling, Simulation, and Scientific Computing. 1(3), 421 (2010).

41. R. Mulyukov, S. Mikhailov, R. Zaripova, and D. Salimonenko. Mat. Res. Bull. 31(6), 639 (1996).

42. V.G. Kul'kov. Technical Physics. The Russian Journal of
Applied Physics. 52(3), 333 (2007).

43. R.R. Mulyukov, A.I. Pshenichnyuk. Metal Science and Heat Treatment. 54(5-6), 244 (2012).

44. R.R. Mulyukov. Metal Science and Heat Treatment. 40, 341 (1998).

45. Yu. K. Favstov, Yu. N. Shulga and A. G. Rakhshtadt. Metallic Material Science of High Damping Alloys, M: Metallurgia. 1980. p. 272 (in Russian). 